\title{
Passive surveillance of Leptospira infection in swine in Germany
}

Katrin Strutzberg-Minder ${ }^{1 *} \mathbb{D}$, Astrid Tschentscher ${ }^{1}$, Martin Beyerbach², Matthias Homuth ${ }^{1}$ and Lothar Kreienbrock ${ }^{2}$

\begin{abstract}
Background: As no current data are available on the prevalence of leptospiral infection in swine in Germany, we analysed laboratory data from diagnostic examinations carried out on samples from swine all over Germany from January 2011 to September 2016. A total of 29,829 swine sera were tested by microscopic agglutination test (MAT) for antibodies against strains of eleven Leptospira serovars.

Results: Overall, 20.2\% (6025) of the total sample collection tested positive for leptospiral infection. Seropositivity ranged between 16.3\% (964) in 2011 and 30.9\% (941) in 2016 (January to September only). Of all samples, 11.6\% (57.3\% of the positives) reacted with only one Leptospira serovar, and only $8.6 \%$ (42.7\% of the positives) reacted simultaneously with two or more serovars. The most frequently detected serovar was Bratislava, which was found in $11.6 \%$ (3448) of all samples, followed by the serovars Australis in 7.3\% (2185), Icterohaemorrhagiae in 4.0\% (1191), Copenhageni in 4.0\% (1182), Autumnalis in 3.7\% (1054), Canicola in 2.0\% (585), and Pomona in 1.2\% (368).

Modelling shows that both the year and the reason for testing at the laboratory had statistically strong effects on the test results; however, no interactions were determined between those factors. The results support the suggestion that the seropositivities found may be considered to indicate the state of leptospiral infections in the German swine population.

Conclusion: Although data from passive surveillance are prone to selection bias, stratified analysis by initial reason for examination and analyses by model approaches may correct for biases. A prevalence of about $20 \%$ for a leptospiral infection is most probable for sows with reproductive problems in Germany, with an increasing trend. Swine in Germany are probably a reservoir host for serovar Bratislava, but in contrast to other studies not for Pomona and Tarassovi.
\end{abstract}

Keywords: Pig, Leptospira, Bratislava, Australis, Icterohaemorrhagiae, Copenhageni, Monitoring, MAT, Seropositivity, Temporal trends

\section{Background}

Leptospirosis is presumed to be the most widespread zoonosis worldwide [1]. It is a cause of reproductive loss in swine breeding herds and has been reported in swine from all parts of the world [2]. Endemic infections in swine herds generally remain subclinical, as do the vast majority of leptospire infections. However, when a susceptible breeding herd is infected for the first time or its immunity is compromised, considerable losses can occur due to abortion, stillbirths, weakly piglets, or infertility. Leptospires persist in the

\footnotetext{
* Correspondence: strutzberg@ivd-gmbh.de

${ }^{1}$ IVD Innovative Veterinary Diagnostics (IVD GmbH), Albert-Einstein-Str. 5,

30926 Seelze, Germany

Full list of author information is available at the end of the article
}

kidneys and genital tract of carrier swine and are excreted in urine and genital fluids [2].

Swine act as maintenance hosts for the serovars belonging to the Pomona and Australis serogroups [3-6], while Icterohaemorrhagiae, Grippotyphosa, and Tarassovi serogroups are among the more commonly identified incidental infections in swine [2]. Serovar Bratislava is endemic in swine in some regions [7-9]. Serological testing is the laboratory procedure most frequently used to confirm the clinical diagnosis, to determine herd prevalence, and to conduct epidemiological studies. The standard serological test is the microscopic agglutination test (MAT). The minimum antigen requirements are that the test should comprise representative strains of all the serogroups known to exist in the particular region as well as 
those known to be maintained elsewhere by the host species. A titre of 100 is taken as positive for the purpose of international trade [10], but given the high specificity of the MAT, lower titres can be taken as evidence of previous exposure to Leptospira. The MAT is used to test individual animals and herds. As an individual animal test, the MAT is very useful (due to its high sensitivity) for diagnosing acute infection: a four-fold rise in antibody titres in paired acute and convalescent serum samples is diagnostic. To obtain useful information from a herd of animals, at least ten animals, or $10 \%$ of the herd, whichever is greater, should be tested for a sufficient sensitivity, and vaccination history should be considered, if vaccines are available $[2,10]$. In Germany no vaccine was registered as of 31 August 2016 [11] and there still is no vaccine for swine available in Germany. However, the use of imported vaccines is allowed with special permission. The MAT has limitations in the diagnosis of chronic infection in individual animals and in the diagnosis of endemic infections in the herds. Infected animals may abort or be renal/genital carriers with MAT titres below the widely accepted minimum significant titre of 100 at final dilution $[2,10]$. Because of all these factors, it is not permissible to express the specificity and sensitivity of the MAT as percentages.

There are only a few recent studies on domestic swine; these report seroprevalences of $55.9 \%$ in pigs in Colombia [12], $16.1 \%$ in pigs in technified swine farms in the state of Alagoas, Brazil [13], 8.6\% in pigs in Korea [14], and $2.7 \%$ in swine in Poland for selected serovars [15]. Furthermore, there are two older studies [16] that report prevalences ranging from $1.2 \%$ for pigs in Germany [17] to $73.3 \%$ in sows in Vietnam (Mekong Delta) [9].

Although leptospirosis is no longer an OIE-listed disease, leptospirosis in swine and sheep is still classified as a notifiable disease and a zoonosis in Germany, but there are no current German data available on this infection in swine. The latest current data in Germany were collected in 1984 and reported in 1987 [17]. Data from a passive surveillance of swine in Germany for infection with leptospires (2003 to 2010) were presented at the EuroLepto 2012 [18].

For this paper we have analysed routine laboratory data from January 2011 to September 2016 for the seropositivity of a total sample collection and subcollections based on the reason for the examination with the aim to estimate the extent of infection of swine in Germany with leptospires and to identify the occurring serovars or serogroups.

\section{Methods}

\section{Sample collection}

Diagnostic examinations were carried out at the diagnostic laboratory of IVD $\mathrm{GmbH}$, Seelze, Germany, on
29,829 serum samples collected from swine from all over Germany between January 2011 and September 2016. All available information about the serum samples, e.g. farm of origin, age/gender of the animal source, was collected with a lab information system (Ticono-LC, Ticono $\mathrm{GmbH}$, Hannover, Germany) and taken into consideration if sufficient information was available. The frequency of samples sent for examination according the geographic origin in Germany was parallel to the density of swine husbandry in Germany (data from further analyses, not published). Samples came from 2571 animal owners for the total study period. We furthermore analysed the samples per herd and per year. Since some farms sent samples for examination in more than one year, the sum of farms sending samples per year is 3953 . It is very likely that most of the samples were from animals kept indoors in stables, because less than $1 \%$ of swine in Germany are housed outdoors, but this was not explicitly reported. And since more than 99\% of swine were housed indoors and no climatic data within the stables were available, seasonal aspects could not be analysed here seriously.

As there was very little or no further information about the sows (such as parity), this was therefore not taken into account for the analyses.

Preliminary information about the samples, such as clinical symptoms or reason for examination, had been systematically requested with the submission form of the laboratory (IVD GmbH, Seelze, Germany) and collected with the Ticono-LC lab information system, but not all senders filled the form out completely. Available information about the samples about the reason for examination was used to identify two subcollections which were analysed in comparison with the total sample collection.

The subcollection "reproductive problems" comprised all samples $(n=12,017)$ of the total population for which any reproductive problem had been reported (checkbox "Reproductive symptoms and/or any comment about reproductive problems" in the form). The subcollection "Monitoring" comprised all samples $(n=1813)$ of the total sample collection for which the checkbox "Examination for monitoring reasons (no clinical symptoms, health check)" was marked and no reproductive problem had been reported.

\section{Laboratory methods}

All samples were tested for leptospiral antibodies by the microscopic agglutination test (MAT) according to the OIE Manual of Diagnostic Tests and Vaccines for Terrestrial Animals 2008 [19] to current editions 2014 [10] using live antigens of Leptospira serovars Australis (strain Ballico), Bratislava (strain Jez Bratislava), Canicola (strain Hond Utrecht IV), Grippotyphosa (strain Moskva V), Copenhageni (strain M20), Icterohaemorrhagiae 
(strain RGA), Pomona (strain Pomona), Hardjo (strain Hardjoprajitno), Saxkoebing (strain Mus 24), and Tarassovi (strain Perepelitsin). In response to an analysis of the frequencies of seropositivity of Leptospira serovars worldwide [16], the serovar Saxkoebing was replaced with Sejroe (strain M 84) in February 2011, and the serovar Autumnalis (strain Akiyami A) was added in April 2011. All strains were supplied by the Leptospirosis Reference Laboratory (at KIT Biomedical Research, The Netherlands). Sera were pretested at the final dilution of $1 / 100$. Sera with $50 \%$ agglutination were retested to determine an endpoint using dilutions of sera beginning at $1 / 25$ through $1 / 3200$. Serum samples with the widely accepted minimum significant titre of 100 (reciprocal of the final dilution of serum with $50 \%$ agglutination) were assessed positive. A farm was considered positive for leptospiral infection if at least one sample per year tested positive by MAT.

\section{Statistical methods}

Data were analysed in two steps. For a general overview, all data were first analysed independently; the positive findings then were analysed both generally (Table 2) and by serovar (Tables 3 and 4). The results are reported as usual frequency statistics.

Next, in order to take into account the hierarchical data structure (repeated samples per farm), all data were analysed in a hierarchical, logistic regression model with two fixed regressors ("year" and "reason for sampling and testing") and a random factor ("farm") (Table 5). From this the strength of association between seropositivity and these factors was estimated via odds ratios (OR) and the asymptotic 95\% confidence intervals (CI) of Woolf and the associated likelihood ratio test (Table 6). All analyses were performed using SAS, version 9.3 TS level 1 M2 (SAS Institute Inc., Cary, NC, United States).

\section{Results}

\section{General description of the sample population}

In general, 29,829 samples from routine laboratory diagnostics were examined from January 2011 to September
2016. Data are from 2571 different farms with some repeated analyses from year to year. These multiple submissions yielded a sum of 3953 farms. Most of the farms (53.8\%) sent four to nine samples per year, followed by $19.0 \%$ of farms with only one to three samples per year, and $18.8 \%$ of farms sending ten to 14 samples per year. The reason for laboratory analysis for each sample is indicated in Table 1. Of the samples for which a reason was given for the examination $(n=13,830), 86.9 \%$ were sent with the information "reproductive problems"; only $13.1 \%$ of the samples were designated as having been taken for "Examination for monitoring reasons (no clinical symptoms, health check)" without any reported reproductive problem.

Overall, there was no information at all about the animal source for $42.2 \%$ of all samples $(n=12,600)$, but there was information for $57.8 \%(n=17,229)$ of the total sample collection. Of the samples with information about the animal source, 95.9\% $(n=16,529)$ were from sows (sows and gilts). (Data not shown).

Only 1813 samples from the entire sample population, i.e. 6.1\%, were identified as having been taken due to monitoring. Overall, the sample population is therefore dominated by samples from sows with reproductive problems. Most of the samples are from farms in Northwest Germany, which is the center of German swine production. All in all, the serological findings do not correspond to a regular prevalence, because the sample collection was not a crosssectional study from the entire German swine production. Nevertheless, the data do give insight into the Leptospira occurrence in German pig farms, because the study included a substantial collection of German pig breeding farms. According to figures from the Federal Statistical Office [20], this represents a mean of $5.9 \%$ of the officially registered German breeding farms per year.

\section{General seropositivity}

A general overview of the results of the serological testing is reported in Table 2. Overall, 20.2\% $(n=6025)$ of

Table 1 Collection of swine serum samples tested for leptospires by MAT

\begin{tabular}{|c|c|c|c|c|c|}
\hline & \multicolumn{3}{|c|}{ Reasons for testing of individual samples } & \multirow[t]{2}{*}{ Total } & \multirow{2}{*}{$\begin{array}{l}\text { Numbe } \\
\text { of farms }\end{array}$} \\
\hline & Monitoring & Reproductive problems & Unknown reasons & & \\
\hline 2011 & 392 & 2514 & 3002 & 5908 & 856 \\
\hline 2012 & 400 & 2422 & 2650 & 5472 & 797 \\
\hline 2013 & 338 & 2249 & 2981 & 5568 & 718 \\
\hline 2014 & 298 & 2087 & 2721 & 5106 & 659 \\
\hline 2015 & 300 & 1582 & 2851 & 4733 & 529 \\
\hline 2016 / 01 to 09 & 85 & 1163 & 1794 & 3042 & 394 \\
\hline Total & 1813 & 12,017 & 15,999 & 29,829 & $3953^{1}$ \\
\hline
\end{tabular}

${ }^{1}$ Because some farms sent samples in more than one year, this number of farms is higher than that of the different farms tested in the total study period 
Table 2 Results of swine serum samples tested for leptospires by MAT. Number (n) of samples examined, numbers ( $n$ ) and percentage (\%) of positive samples and farms with at least one positive sample per farm and year from January 2011 to September 2016, and totals

\begin{tabular}{|c|c|c|c|c|c|c|}
\hline \multirow[t]{2}{*}{ Year } & \multirow{2}{*}{$\begin{array}{l}\text { Number } \\
\text { of serum } \\
\text { samples }\end{array}$} & \multicolumn{2}{|c|}{ Positives $^{a}$} & \multirow{2}{*}{$\begin{array}{l}\text { Number } \\
\text { of farms }\end{array}$} & \multicolumn{2}{|c|}{ Positives $^{b}$} \\
\hline & & $\mathrm{n}$ & $\%$ & & $n$ & $\%$ \\
\hline 2011 & 5908 & 964 & 16.3 & 856 & 508 & 59.3 \\
\hline 2012 & 5472 & 1042 & 19.0 & 797 & 509 & 63.9 \\
\hline 2013 & 5568 & 1076 & 19.3 & 718 & 434 & 60.4 \\
\hline 2014 & 5106 & 993 & 19.5 & 659 & 416 & 63.1 \\
\hline 2015 & 4733 & 1009 & 21.3 & 529 & 375 & 70.9 \\
\hline 2016 / 01 to 09 & 3042 & 941 & 30.9 & 394 & 308 & 78.2 \\
\hline Total & 29,829 & 6025 & 20.2 & 3953 & 2550 & 64.5 \\
\hline
\end{tabular}

${ }^{\mathrm{a}}$ Samples with a titre $\geq 100$

${ }^{b}$ farms with at least one positive sample per year

all 29,829 swine serum samples tested positive by MAT. The seropositivity ranged between $16.3 \%$ ( $\mathrm{n}=$ $964)$ in 2011 and $30.9 \%(n=941)$ in 2016 (January to September). A total of $64.5 \%$ farms tested positive for leptospires by at least one sample per year. The percentage of farms with positive test results ranged between 59.3\% $(\mathrm{n}=508)$ in 2011 and $78.2 \%(\mathrm{n}=308)$ in 2016. Forecasting 4056 samples for all of 2016, the mean number of samples was 5141 per year, with moderate variation in seropositivity from year to year (Table 2).

Analysis of the reactivity of the serum samples with different serovars (Table 3) showed that $11.6 \%$ of all samples examined, comprising $57.3 \%$ of the positives, reacted with only one serovar, whereas $42.7 \%$ reacted simultaneously with two or more serovars.

Table 3 Simultaneous reactivity of swine serum samples by MAT with various Leptospira serovars. (Data from January 2011 to September 2016)

\begin{tabular}{lll}
\hline $\begin{array}{l}\text { Reactivity with different serovars } \\
\text { (number of serovars) }\end{array}$ & $\begin{array}{l}\text { Number of } \\
\text { serum samples }\end{array}$ & $\begin{array}{l}\text { Percentage of } \\
\text { all samples }\end{array}$ \\
\hline 0 & 23,804 & 79.8 \\
1 & 3454 & 11.6 \\
2 & 1617 & 5.4 \\
3 & 524 & 1.8 \\
4 & 201 & 0.7 \\
5 & 95 & 0.3 \\
6 & 69 & 0.2 \\
7 & 41 & 0.1 \\
8 & 16 & 0.1 \\
9 & 7 & 0.0 \\
10 & 1 & 0.0 \\
Total & 29,829 & 100.0 \\
\hline
\end{tabular}

\section{General occurrence of serovars and variations from year} to year

The most frequently detected serovar was Bratislava (Table 4$)$, which was found in $11.6 \%(n=3448)$ of all samples, followed by the serovars Australis in 7.3\% $(n=2185)$, Icterohaemorrhagiae in $4.0 \%(n=1191)$, Copenhageni in $4.0 \%(n=1182)$, Autumnalis in $3.7 \%(n=1054)$, Canicola in $2.0 \%(n=585)$, and Pomona in $1.2 \%(n=368)$. All other serovars were detected less often (in $<1.0 \%$ of all samples). Total reactivity is more than $100.0 \%$ because of the possibility of multiple positive reactions with different serovars.

\section{Trends in seropositivity in time and subcollections}

This model (Table 5) shows a strong, statistically significant effect of the year of analysis (general $\mathrm{p}=<.0001$ ). Starting in 2011 as a reference, the seropositivity was statistically significantly increased in 2012, 2015, and 2016. In addition, the reason for laboratory analyses influenced the results (general $\mathrm{p}=0.0005$ ): in contrast to samples from monitoring, those from animals with reproductive problems were 1.5 times more likely to be positive. Due to the same order of effect for samples of unknown reason, it may be inferred that those were from sows with reproductive problems, as well. However, no interaction was found between year and reason for sampling $(\mathrm{p}=0.1049)$, which supports the suggestion that there was a real expansion of Leptospira in the German swine population. These models support the evidence that Leptospira infections increased over time.

To compensate for a selection bias in these analyses, trends in time were analysed separately by means of the logistic regression in the stratum of reason for sampling (see Table 6).

The results (Table 6) show time effects very similar to those in the general model from Table 5, indicating the presence of a general trend over time. This effect is different in the monitoring group in contrast to both the stratum with reproduction problems as well as in the subgroup with unknown reason for sampling. Nevertheless, both trends are very similar, indicating that it is likely that most of the unknowns are due to reproductive problems, as well.

\section{Discussion}

Because research results on the incidence of leptospire infections in domestic pigs are either old, scarce, or both, this study used existing diagnostic data in order to obtain current evidence about the infection of swine with leptospires in Germany. The advantage of the present approach is that it yielded a large number of results. Of course, the disadvantage of this approach is that the sample collection is not representative. In light of biases due to the structure of data from routine diagnostic examinations, logistic regression analyses were undertaken including additional 
Table 4 Number and percentage of swine serum samples that tested positive by MAT for Leptospira serovar. (Data from January 2011 to September 2016)

\begin{tabular}{|c|c|c|c|c|}
\hline Serogroup & Serovar & $\begin{array}{l}\text { Number of positive } \\
\text { serum samples }\end{array}$ & $\begin{array}{l}\text { Percentage of the positives } \\
\text { (samples tested positive in total: } 6025 \text { ) }\end{array}$ & $\begin{array}{l}\text { Percentage of all tested } \\
\text { (samples tested in total: 29,829) }\end{array}$ \\
\hline \multirow[t]{2}{*}{ Australis } & Australis & 2185 & 36.3 & 7.3 \\
\hline & Bratislava & 3448 & 57.2 & 11.6 \\
\hline Autumnalis & $\begin{array}{l}\text { Autumnalis }{ }^{\mathrm{a}} \\
\text { (tested: } 28,189, \text { positive: } 5735 \text { ) }\end{array}$ & 1054 & 18.4 & 3.7 \\
\hline Canicola & Canicola & 585 & 9.7 & 2.0 \\
\hline Grippotyphosa & Grippotyphosa & 230 & 3.8 & 0.8 \\
\hline \multirow[t]{2}{*}{ Icterohaemorrhagiae } & Copenhageni & 1182 & 19.6 & 4.0 \\
\hline & Icterohaemorrhagiae & 1191 & 19.8 & 4.0 \\
\hline Pomona & Pomona & 368 & 6.1 & 1.2 \\
\hline \multirow[t]{2}{*}{ Sejroe } & Hardjo & 35 & 0.6 & 0.1 \\
\hline & $\begin{array}{l}\text { Sejroe } \\
\text { (tested: } 29,247, \text { positive: } 5902 \text { ) }\end{array}$ & 9 & 0.2 & 0.0 \\
\hline Tarassovi & Tarassovi & 151 & 2.5 & 0.5 \\
\hline
\end{tabular}

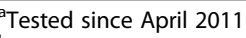

${ }^{\mathrm{b}}$ Tested since February 2011

information about the farm and stratification by the reason for testing; in this way the biases could be compensated for, and it was shown that the seropositivities of the present study are plausible estimations for the occurrence of Leptospira in the German swine population.

Table 5 Two-factor logistic regression analysis on MAT outcome

\begin{tabular}{|c|c|c|c|c|c|c|}
\hline \multicolumn{7}{|c|}{ General model type III tests of fixed effects } \\
\hline & \multicolumn{2}{|c|}{$\mathrm{DF}^{\mathrm{a}}$} & \multicolumn{2}{|l|}{$F^{b}$} & \multicolumn{2}{|l|}{$p^{c}$} \\
\hline Year & \multicolumn{2}{|l|}{5} & \multicolumn{2}{|l|}{10.79} & \multicolumn{2}{|c|}{$<.0001$} \\
\hline Reason for sampling & \multicolumn{2}{|l|}{2} & \multicolumn{2}{|l|}{7.66} & \multicolumn{2}{|l|}{0.0005} \\
\hline Interaction & \multicolumn{2}{|l|}{10} & \multicolumn{2}{|l|}{1.58} & \multicolumn{2}{|l|}{0.1049} \\
\hline \multirow[t]{2}{*}{ Effect } & \multirow[t]{2}{*}{$n$} & \multirow[t]{2}{*}{ Positives \% } & \multirow[t]{2}{*}{$O R^{d}$} & $\mathrm{Cl}^{\mathrm{e}}$ & & \multirow[t]{2}{*}{$p^{f}$} \\
\hline & & & & lower & upper & \\
\hline \multicolumn{7}{|l|}{ Year } \\
\hline 2011 (ref) & 5908 & 16.3 & 1 & - & - & - \\
\hline 2012 & 5472 & 19.0 & 1.490 & 1.204 & 1.843 & 0.0023 \\
\hline 2013 & 5568 & 19.3 & 1.251 & 0.996 & 1.572 & 0.1292 \\
\hline 2014 & 5106 & 19.5 & 1.296 & 1.026 & 1.638 & 0.1935 \\
\hline 2015 & 4733 & 21.3 & 1.951 & 1.549 & 2.457 & 0.0014 \\
\hline 2016 / 01 to 09 & 3042 & 30.9 & 2.565 & 1.862 & 3.533 & 0.0240 \\
\hline \multicolumn{7}{|l|}{ Reason for sampling } \\
\hline Monitoring (ref) & 1813 & 16.9 & 1 & - & - & - \\
\hline $\begin{array}{l}\text { Reproductive } \\
\text { problems }\end{array}$ & 12,017 & 22.1 & 1.478 & 1.189 & 1.838 & 0.0017 \\
\hline Unknown reasons & 15,999 & 19.1 & 1.326 & 1.068 & 1.646 & 0.0093 \\
\hline
\end{tabular}

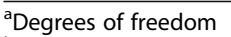

${ }^{\mathrm{b}} \mathrm{F}$-test statistics for model parameter

${ }^{c} p$-value for F-Test

odds ratios adjusted for year, reason for sampling, and interaction

elower/upper bound $95 \%$ confidence interval for the odds ratio

${ }^{\mathrm{f}} p$-value for Wald test
Available epidemiological studies about leptospirosis in swine are very heterogeneous, due to regional differences and to differences in the evaluation of diagnostic (e.g. different serovars used for testing) and population studies. In the collection of our investigation we found an overall seropositivity of $20.2 \%$, with an increasing trend over time. A similar seroprevalence of $16.1 \%$ [13] has been found in 342 pigs in five districts in the state of Alagoas, Brazil, but in contrast to our results the most frequent serovar there was Icterohaemorrhagiae $(41.8 \%$ of the 55 positives), followed by Autumnalis (29.1\%) and Bratislava (9.1\%), which was the most frequent serovar in our present study (57.2\% of positives).

A recent study about the prevalence of antibodies to selected Leptospira serovars in swine from Poland $(n=22,883)$ showed prevalences of only $1.32 \%$ to $2.68 \%$ within the very similar time period of 2011 to 2015; there, the most frequent serovars were Pomona (varying between $0.39 \%$ to $1.13 \%$ ) and Sejroe (decreasing from $1.12 \%$ to $0.18 \%$ ), but it was not tested for antibodies against the serovar Bratislava in that study [21]. In our study, seroprevalences for Pomona were slightly higher, while those for Sejroe were much lower. Results show that, even in geographically similar or close regions, overall prevalences of Leptospira infections may be similar, while the frequency of serovars may vary substantially. Differences in the frequency of serovars may be additionally caused by infection dynamics over periods of time due to the population density of the wildlife reservoir hosts and climatic conditions (mean air temperature $\geq 18{ }^{\circ} \mathrm{C}$ and periods of heavy rain).

More than half $(57.3 \%)$ of the positive porcine sera reacted by MAT with a single serovar, presumably indicating the infection causing serovar and the chronic 
Table 6 One-factor logistic regression analyses on MAT outcome. Stratified by reason for sampling

\begin{tabular}{|c|c|c|c|c|c|c|}
\hline \multirow[t]{2}{*}{ Effect } & \multirow[t]{2}{*}{ number } & \multirow{2}{*}{$\begin{array}{l}\text { Positives } \\
\%\end{array}$} & \multirow[t]{2}{*}{$O R^{a}$} & \multicolumn{2}{|l|}{$\mathrm{Cl}^{\mathrm{b}}$} & \multirow[t]{2}{*}{$p^{c}$} \\
\hline & & & & lower & upper & \\
\hline \multicolumn{7}{|c|}{ Reason: monitoring } \\
\hline 2011 (ref) & 392 & 9.2 & 1 & - & - & - \\
\hline 2012 & 400 & 20.5 & 2.450 & 1.386 & 4.331 & 0.0022 \\
\hline 2013 & 338 & 15.1 & 1.623 & 0.876 & 3.007 & 0.1231 \\
\hline 2014 & 298 & 15.8 & 1.538 & 0.818 & 2.895 & 0.1806 \\
\hline 2015 & 300 & 23.7 & 2.768 & 1.496 & 5.123 & 0.0013 \\
\hline $2016 / 01$ to 09 & 85 & 23.5 & 2.840 & 1.161 & 6.948 & 0.0224 \\
\hline \multicolumn{7}{|c|}{ Reason: reproductive problems } \\
\hline 2011 (ref) & 2514 & 18.0 & 1 & - & - & - \\
\hline 2012 & 2422 & 18.3 & 1.051 & 0.863 & 1.280 & 0.6223 \\
\hline 2013 & 2249 & 20.5 & 1.071 & 0.874 & 1.312 & 0.5075 \\
\hline 2014 & 2087 & 23.8 & 1.326 & 1.081 & 1.627 & 0.0068 \\
\hline 2015 & 1582 & 27.6 & 1.679 & 1.355 & 2.080 & $<.0001$ \\
\hline $2016 / 01$ to 09 & 1163 & 32.0 & 2.301 & 1.822 & 2.906 & $<.0001$ \\
\hline \multicolumn{7}{|c|}{ Reason: unknown } \\
\hline 2011 (ref) & 3002 & 15.9 & 1 & - & - & - \\
\hline 2012 & 2650 & 19.6 & 1.284 & 1.055 & 1.562 & 0.0127 \\
\hline 2013 & 2981 & 18.9 & 1.131 & 0.928 & 1.377 & 0.2233 \\
\hline 2014 & 2721 & 16.5 & 1.076 & 0.878 & 1.319 & 0.4813 \\
\hline 2015 & 2851 & 17.6 & 1.603 & 1.296 & 1.983 & $<.0001$ \\
\hline $2016 / 01$ to 09 & 1794 & 30.6 & 2.585 & 2.078 & 3.215 & $<.0001$ \\
\hline
\end{tabular}

${ }^{a}$ Odds ratios adjusted for year, reason, and interaction

${ }^{\mathrm{b}}$ lower/upper bound $95 \%$ confidence interval for the odds ratio

${ }^{c} p$-value for Wald test

stage of infection, so that ultimately it is to be assumed that $11.6 \%$ of the examined pigs were chronically infected by Leptospira [22]. On the other hand, $42.7 \%$ of the positive porcine sera reacted simultaneously with two or more serovars, indicating both cross-reactions of serovars of the same serogroup and the acute phase of infection, because of the induction of antibodies against common antigens of Leptospira in the first phase of infection. Moreover, paradoxical immune response occurs in the state of acute infection, meaning that $3.2 \%$ of all pigs examined in this investigation were very likely in an acute stage of infection (reactions with three or more serovars simultaneously, as two serovars at most belong to one serogroup) [22]. Considering that the MAT is a not a perfect test, in that it is highly specific, but of low sensitivity in case of chronic and endemic infections [10], the seropositivities of this study are very likely underestimated.

Because of the different epidemiology of the serovars or serogroups, each serovar tested in this study will be discussed separately:
On the basis of these results and those of earlier analyses [18], Bratislava is apparently still endemic in pigs in Germany, where pigs are a reservoir host for this serovar, as is the case in many countries and regions worldwide [16]. As venereal transmission is thought to play an important role in the spread of Bratislava infection, this is the most critical factor in control of the infection. Nevertheless, because of the difficulties in culturing these strains [17] and the inability thus far to identify the serovar by detection of leptospires via PCR techniques, Bratislava infections of swine still remain poorly understood [2].

Although the reported percentages of the positives for serovar Pomona are in general not higher than 6 . $5 \%(6.1 \%$ in this study), with a few exceptions [12, 23] Pomona in particular is nevertheless still found in cases with documented abortions in Germany [24]; unfortunately no newer data are available. The diagnostic services of IVD $\mathrm{GmbH}$, Seelze, Germany, reported a few cases of abortions per year with strong indication that these were caused by Pomona (personal communication). Because of these occasional outbreaks of clinical disease in contrast to widespread clinical disease of swine-adapted strains it is assumed that these strains are rodent maintained [2, 25, 26].

The pig was previously thought to act as a maintenance host for some strains of the serovar Tarassovi found in eastern Europe and Australia [2], but declining seroprevalences in most of the studies $[16,21]$ as well as values of $0.5 \%$ observed overall in this study support the view that Tarassovi infections are incidental infections of pigs resulting from wildlife contact and that the swine is no longer a reservoir for this serovar.

Although leptospires belonging to the serogroup Canicola have been recovered from swine in a number of countries[2, 27], little is known about the epidemiology of serovar Canicola infection in pigs. Dogs are recognized as the maintenance host for this serovar but wildlife may also be a source of infection. Long periods of urine shedding observed in infected pigs and the ability of Canicola to survive in undiluted pig urine suggest that intraspecies transmission occurs [2]. Although seroprevalences for serovar Canicola worldwide in general are not higher than $1.5 \%$ $[9,16]$, it was nevertheless the most frequent serovar in a study on an area of the Colombian tropics in pigs (62. $4 \%)$ and in humans (64.5\%), and less frequent in dogs (14.1\%) [12]. Furthermore, an overall seroprevalence of $2.0 \%$ with a continuous, statistically significant increase over time was observed in the present study. Because of generally high biosecurity levels in German pig herds, it is unlikely that pigs could be infected with serovar Canicola via dogs or wildlife. Further studies should therefore be performed to investigate the entry of serovar Canicola into pig herds in Germany. 
Serological evidence of Icterohaemorrhagiae serogroup infection has been reported in many countries with different frequencies [16], but few isolations have been made from pigs [2]. Both serovars Copenhageni and Icterohaemorrhagiae may be involved, as is supported by our data with overall seropositivities of 4 . $0 \%$ and $4.0 \%$, corresponding to $19.6 \%$ and $19.8 \%$ of the positives, respectively. It is probable that both serovars were introduced to susceptible herds via an environment contaminated with urine from the infected brown rat (Rattus norvegicus), which is the maintenance host for these serovars. Rodents have been suspected in infections with Icterohaemorrhagiae in swine farms in Brazil, as well [13].

Serovar Grippotyphosa infection is maintained by wildlife hosts, and incidental infection of pigs gives rise to low prevalences in some regions, particularly in eastern and central Europe and the United States [2], as also observed in the present study $(0.8 \%$ overall). A human Leptospira outbreak with serovar Grippotyphosa among strawberry pickers in Germany in the summer of 2007 was in all likelihood due to transmission via field mouse (Microtus arvalis) [28]. Depending on appropriate climatic conditions for leptospires and the population density of these mice, there is a risk of infection with leptospires via field mouse on any farm.

The seropositivity of serovar Hardjo in pigs of this study was very low $(0.1 \% ; 35 / 29829)$, whereas it was the most frequent serovar (3.1\%) in wild boars in Poland [29]. Furthermore, serovar Sejroe, which like serovar Hardjo belongs to the serogroup Sejroe, was very rarely detected serologically $(0.0 \% ; 9 / 29247)$ in this study, whereas it was the most common serovar in swine in Poland, although at a low level of prevalence $(1.12 \%$ for 2011 to $0.18 \%$ for 2015) [15]. Serovar Hardjo is maintained worldwide by cattle, and infection of pigs with Hardjo occurs where cattle and pigs come in close contact. Simultaneous husbandry of cattle and swine has become rare in Germany, so the risk of an infection with serovar Hardjo for pigs is low in that country, as is supported by the data of this study (seropositivity of $0.1 \%$ ).

Analysis of the literature showed serious seroprevalences of serovar Autumnalis in pigs worldwide [16]. Results of this study, showing overall seropositivities of $3.7 \%$ with an increasing trend, confirm the need for testing of swine for antibodies against serovar Autumnalis, for which rodents or other wildlife are presumed to be the main reservoir.

Overall, interruption of transmission from infected pig or other host to the pig remains the critical factor in the control of leptospires.

\section{Conclusion}

Infection of pigs with leptospires is obviously a dynamic process. Analyses of data from passive surveillance within routine diagnostic examinations are useful for obtaining an indication of the distribution of Leptospira and their serovars in domestic swine in a region in general and over time. Information about the reason for examination and the farms or herds (size and type) and animal (age and gender, clinical status) at diagnostic testing would enable an improvement in epidemiological analysis which could also be helpful for the swine veterinary practitioner. Logistic regression model approaches may compensate for the biases arising from passive surveillance data (hierarchical structures of farms, sampling strategy). Finally, this is an appeal to every swine veterinary practitioner to provide all available information about the animals and the herd in order to enable a good diagnosis and improve epidemiological analyses.

Based on these results, further active surveillance of swine in Germany for infections with leptospires should be advised. Attention should furthermore also continue to be paid to subclinical leptospiral infections as well as leptospirosis in breeding pigs and in proliferation of pigs together with their hosted infectious agents. It is strongly recommended to maintain awareness about subclinical leptospiral infections and leptospirosis in conjunction with the handling of pigs by animal owner, stockman, veterinarian, etc. However, any human, from dog owner to aquatic sportsman, can also be exposed to many other infectious sources, including other reservoir hosts (e.g. field mouse, $\operatorname{dog}$ ) and water and soil contaminated with leptospires under optimal climatic conditions.

For better comparison of epidemiological studies about seroprevalences of leptospiral infection in swine, the serovars Bratislava, which has emerged as the major swine-maintained leptospiral infection, and Pomona, which causes clinical disease, should always be included in the examinations by MAT. It is also recommended that further serovars, like Icterohaemorrhagiae, Copenhageni, Autumnalis, Grippotyphosa, and Canicola, which are involved in incidental infections in swine by maintenance in other animal species, be included in the serovar collection of MAT for pigs in Germany and perhaps even in bordering countries or regions with similar pig management structures, because of the easy transmission by rodents and other wildlife close to swine husbandry facilities.

\section{Acknowledgements \\ The authors thank David Goldstein and Dr Karen Dohmann for their technical support in the laboratory performing the MAT. We are also grateful to Dr Jan Böhmer for critical review of the text and inspiring comments about our work, to Judith McAlister-Hermann, PhD, for English editorial support, and to Dr Robert Tabeling and Dr Susanne Münzer-Rach, Intervet Deutschland GmbH, Unterschleissheim, as the initiators of this epidemiological study.} $\mathrm{GmbH}$, Unterschleissheim, Germany. 


\section{Availability of data and materials}

The datasets analysed during the current study are available from the corresponding author on reasonable request.

\section{Authors' contributions}

AT extracted all pertinent data from the lab information system, calculated all data, and helped in the preparation of diagrams. KSM analysed all data, prepared most of the tables, and wrote the manuscript. MB checked all data and calculations and performed the statistical analyses. MH assumed additional work loads in order to allow KSM to realize this extensive project. LK provided support in the results and interpretation of the statistical findings and reviewed the manuscript critically. All authors read and approved the final manuscript.

\section{Ethics approval and consent to participate}

The present research does not include experimental data and all laboratory analyses were performed on data from previous examinations of swine for routine diagnostics. The study was submitted for evaluation of its ethical aspects to the Animal Welfare Officer of the University of Veterinary Medicine Hannover, who has confirmed that approval by an animal ethics committee is not applicable or required in this case.

\section{Consent for publication}

Not applicable.

\section{Competing interests}

The authors declare that they have no competing interests.

\section{Publisher's Note}

Springer Nature remains neutral with regard to jurisdictional claims in published maps and institutional affiliations.

\section{Author details}

'IVD Innovative Veterinary Diagnostics (IVD GmbH), Albert-Einstein-Str. 5, 30926 Seelze, Germany. ${ }^{2}$ Institute for Biometry, Epidemiology and Information Processing (IBEI), WHO Collaborating Center for Research and Training for Health at the Human-Animal-Environment Interface, University of Veterinary Medicine Hannover, Foundation, Bünteweg 2, 30559 Hannover, Germany.

\section{Received: 8 March 2017 Accepted: 21 November 2017}

Published online: 27 March 2018

\section{References}

1. Adler B, de la Pena Moctezuma A. Leptospira and leptospirosis. Vet Microbiol. 2010;140:287-96.

2. Ellis WA. Leptospirosis. In: Zimmermann JJ, Karriker LA, Ramirez A, Schwartz KJ, Stevenson GW, editors. Diseases of swine. Wiley; 2012. p. 1562-79.

3. Bolin CA. Diagnosis of leptospirosis in swine. JSHAP. 1994;2:23-4.

4. Adler B. Leptospira and Leptospirosis. Berlin Heidelberg: Springer; 2015.

5. WHO. Human leptospirosis: guidance for diagnosis, surveillance and control. WHO library cataloguing-in-publication data: World Health Organisation. http://www.who.int/csr/don/en/WHO_CDS_CSR_EPH_2002.23.pdf; 2003.

6. Spickler AR, Leedom Larson KR. Leptospirosis. http://www.cfsph.iastate.edu/ Diseaselnfo/disease.php?name=leptospirosis\&lang=en. 2013.

7. Ellis WA, MCParland PJ, Bryson DG, Cassells JA. Boars as carriers of leptospires of the Australis serogroup on farms with an abortion problem. Vet Rec. 1986;118:563.

8. Cisneros Puebla MA, Moles Cervantes LP, Rosas DG, Serrania NR, Torres Barranca J. Diagnostic serology of swine leptospirosis in Mexico 1995-2000. Rev Cubana Med Trop. 2002;54:28-31.

9. Boqvist S, Chau BL, Gunnarsson A, Olsson EE, Vagsholm I, Magnusson U. Animal- and herd-level risk factors for leptospiral seropositivity among sows in the Mekong delta, Vietnam. Prev Vet Med. 2002;53:233-45.

10. OIE. Manual of diagnostic tests and vaccines for terrestrial animals. Leptospirosis. Chapter 2.1.12: World Organisation for Animal Health; 2014. http://www.oie.int/fileadmin/Home/eng/Health_standards/tahm/2.01.12_ LEPTO.pdf. May 2014.

11. PEl list of registered vaccines for swine: Paul-Ehrlich-Institut. http://www.pei. de/DE/arzneimittel/impfstoff-impfstoffe-fuer-tiere/schweine/schweine-node. html. Updated: 6 Dec 2016
12. Calderon A, Rodriguez V, Mattar S, Arrieta G. Leptospirosis in pigs, dogs, rodents, humans, and water in an area of the Colombian tropics. Trop Anim Health Prod. 2014;46:427-32.

13. Valenca RM, Mota RA, Castro V, Anderlini GA, Pinheiro Junior JW, Brandespim DF, Valenca SR, Guerra MM. Prevalence and risk factors associated with Leptospira spp. infection in technified swine farms in the state of Alagoas, Brazil: risk factors associated with Leptospira spp. in swine farms. Transbound Emerg Dis. 2013;60:79-86.

14. Jung BY, Park CK, Lee CH, Jung SC. Seasonal and age-related seroprevalence of Leptospira species in pigs in Korea. Vet Rec. 2009;165:345-6.

15. Zebek S, Nowak A, Borowska D, Zmudzki J, Jablonski A. Prevalence of antibodies to selected Leptospira serovars in swine in Poland. Dublin: Poster and Abstract (PO-PF-031; p264) at 24th International Pig Veterinary Society Congress, 8th European Symposium of Porcine Health Management; 2016.

16. Strutzberg-Minder K, Kreienbrock L. Leptospire infections in pigs: epidemiology, diagnostics and worldwide occurrence. Berl Munch Tierarztl Wochenschr. 2011;124:345-59.

17. Schonberg A, Staak C, Kampe U. Leptospirosis in West Germany. Results of a research program on leptospirosis in animals in the year 1984. Zentralbl Veterinarmed B. 1987;34:98-108.

18. Strutzberg-Minder K, Tschentscher A, Hartmann M, Beyerbach M, Kreienbrock L. Passive surveillance of swine in Germany for infection with Leptospires. Dubrovnik: Oral presentation and abstract (OP 4; p27-28) at European meeting on leptospirosis; 2012.

19. OIE. Manual of diagnostic tests and vaccines for terrestrial animals. Leptospirosis. Chapter 2.1.9: World Organisation for Animal Health. Paris: OIE-Manual; 2008

20. Genesis Online Datenbank. Statistisches Bundesamt (Destatis) 2016; https:// www-genesis.destatis.de/genesis/online;jsessionid= EB05C7801EE3AB5B99B904924D93E5CC.tomcat_GO_2_1?operation= previous\&levelindex $=4 \&$ levelid $=1521627691197 \&$ step $=4$. Accessed 16 Nov 2017.

21. Wasinski B. Occurrence of Leptospira sp. antibodies in swine in Poland. Bull Vet Inst Pulawy. 2007;51:225-8.

22. Levett PN. Leptospirosis. Clin Microbiol Rev. 2001:14:296-326.

23. Al-Khleif A, Damriyasa IM, Bauer C, Menge C, Herbst W. A serosurvey for infections with Leptospira serovars in pigs from Bali, Indonesia. Dtsch Tierarztl Wochenschr. 2009;116:389-91.

24. Waldmann KH. Progression and control of leptospirosis in a sow herd. Dtsch Tierarztl Wochenschr. 1990;97:39-42.

25. Barlow AM. Reproductive failure in sows associated with Leptospira Mozdok from a wildlife source. Pig J. 2004:54:123-31.

26. Rocha T. Isolation of leptospira interrogans serovar Mozdok from aborted swine fetuses in Portugal. Vet Rec. 1990;126:602.

27. Paz-Soldan SV, Dianderas MT, Windsor RS. Leptospira interrogans serovar Canicola: a causal agent of sow abortions in Arequipa, Peru. Trop Anim Health Prod. 1991;23:233-40.

28. Jansen A, van Treeck U. Die Rückkehr des Feldfiebers in Deutschland: Leptospira-Grippotyphosa-Ausbruch unter Erbeerpflückern. Epidemiologisches Bulletin. 2008;11:85-8. Robert-Koch-Institut. https://www. rki.de/DE/Content/Infekt/EpidBull/Archiv/2008/Ausgaben/11_08.pdf?_blob= publicationFile. Mar 2008

29. Zmudzki J, Jablonski A, Nowak A, Zebek S, Arent Z, Bocian L, et al. First overall report of Leptospira infections in wild boars in Poland. Acta Vet Scand. 2016:58:3.

\section{Submit your next manuscript to BioMed Central} and we will help you at every step:

- We accept pre-submission inquiries

- Our selector tool helps you to find the most relevant journal

- We provide round the clock customer support

- Convenient online submission

- Thorough peer review

- Inclusion in PubMed and all major indexing services

- Maximum visibility for your research

Submit your manuscript at www.biomedcentral.com/submit 